\title{
Gene dosage PCR and fluorescence in situ hybridization reveal low frequency of egfr amplifications despite protein overexpression in invasive breast carcinoma
}

\author{
Christian Kersting ${ }^{1}$, Nicola Tidow ${ }^{2}$, Hartmut Schmidt ${ }^{2}$, Cornelia Liedtke ${ }^{1}$, Joerg Neumann ${ }^{1}$, \\ Werner Boecker ${ }^{1}$, Paul J van Diest ${ }^{3}$, Burkhard Brandt ${ }^{2}$ and Horst Buerger ${ }^{1}$ \\ ${ }^{1}$ Institute of Pathology; ${ }^{2}$ Institute of Clinical Chemistry and Laboratory Medicine, University of Muenster, \\ Muenster, Germany and ${ }^{3}$ Department of Pathology, University Medical Center Utrecht, Utrecht, \\ The Netherlands
}

\begin{abstract}
The aim of this study was to assess the frequency of egfr whole gene and CA intron repeat amplification in invasive breast cancer as a mechanism for epidermal growth factor receptor (EGFR) protein overexpression. By means of tissue microarrays, protein overexpression and whole gene amplification were assessed in 222 cases of invasive breast cancer by immunohistochemistry and FISH, respectively. First intron CA repeat amplification was assessed by Taqman RT-PCR. With FISH and RT-PCR, 4.7 and $6.3 \%$ of cases showed whole gene and first intron CA repeat amplification, respectively. Amplification dosage varied between two- and four-fold in RT-PCR. By immunohistochemistry, 17.3\% showed EGFR overexpression. There was a low correlation between the different methods. In all, $2.9 \%$ of cases showed both whole gene amplification and intron CA repeat amplification, and $\mathbf{9 0 . 3 \%}$ of cases were negative for both. Nearly $20 \%$ of cases with immunohistochemical protein overexpression showed intron CA repeat amplification, and only $2.2 \%$ of cases that were negative on immunohistochemistry showed such amplification. In all, $13 \%$ of cases with protein overexpression showed amplification by FISH, and only $1.6 \%$ of cases that were negative on immunohistochemistry showed such amplification. Of the cases with EGFR overexpression, $4(25 \%)$ showed either whole gene or intron CA repeat amplification. In conclusion, whole gene amplifications of egfr are rare in invasive breast cancer and explain protein overexpression in only about $12.5 \%$ of invasive breast cancer cases. First intron first CA repeat amplification is another important mechanism for EGFR protein overexpression, explaining protein overexpression in about $18.7 \%$ of cases. However, since about $75 \%$ of cases with EGFR protein overexpression lack either of these amplifications, other expression regulating mechanisms must be considered.
\end{abstract}

Laboratory Investigation (2004) 84, 582-587, advance online publication, 15 March 2004; doi:10.1038/labinvest.3700077

Keywords: EGFR; amplification; overexpression; breast; carcinoma; gene dosage PCR; IH; FISH

The epidermal growth factor receptor (EGFR) is a $170-\mathrm{kDa}$ transmembrane glycoprotein of the $c$-erbB receptor family with tyrosine kinase activity. Specific ligands comprise the epidermal growth factor and transforming growth factor-alpha. The receptor has a central position in cellular regulation mechanisms involving proliferation, differentiation, angiogenesis and motility of normal and cancer cells. The overexpression of the receptor protein confers a

Correspondence: Dr H Büerger, MD, PhD, Institute of Pathology, Westfälische Wilhelmsuniversität Münster, Albert-SchweitzerStreet. 33, 48149 Münster, Germany.

E-mail: burgerh@uni-muenster.de

Received 20 October 2003; revised 20 January 2004; accepted 23 January 2004; published online 15 March 2004 transformed phenotype to NIH 3T3 cells ${ }^{1}$ and could be demonstrated in various human malignancies. Different authors reported egfr amplifications in $0-15 \%$ of human breast carcinomas ${ }^{2,3}$ and EGFR protein overexpression in $16.4 \%{ }^{4}$ Although, numerous studies have shown its prognostic significance ${ }^{4-7}$ the most recent literature characterized EGFR as a factor of doubtful prognostic significance in human breast cancer. ${ }^{8}$ Nevertheless, with the introduction of anti-EGFR-based therapeutic regimes, including monoclonal antibodies, synthetic tyrosine kinase inhibitors and ligand-linked toxins, ${ }^{9}$ the predictive character of EGFR comes more into focus. ${ }^{10}$ Some of these agents are already under intense investigation in clinical trials ${ }^{11,12}$ and some have shown promising results (Figure 1). 



Figure 1 Photomicrographs of a tumor without EGFR overexpression (a) and a positive sample with strong membrane staining for EGFR (b)

Protein overexpression of EGFR at the cellular membrane is critical in the success of these new forms of targeted therapy. However, the mechanisms which lead to EGFR overexpression are poorly understood. In analogy to erbB2, the amplification of the whole gene was initially thought to be the major mechanism, even though large tumor series concerning this hypothesis have not been published yet. Also, post-translational changes as well as changes in genetic enhancer elements ${ }^{13,14}$ were shown to be associated with an increased EGFR expression. Recently, a polymorphic CA-repeat in intron 1 of egfr has been shown to have an important impact on egfr transcription and expression, too and seems to be a major target of egfr mutations ${ }^{15}$ (Figure 2).

In order to gain an overview about the frequency of egfr amplifications and EGFR-overexpression in invasive breast cancer, we compared gene dosage real-time PCR of a highly variable polymorphic genetic site within egfr with fluorescence in situ hybridization (FISH) and immunohistochemistry in a large breast cancer series.
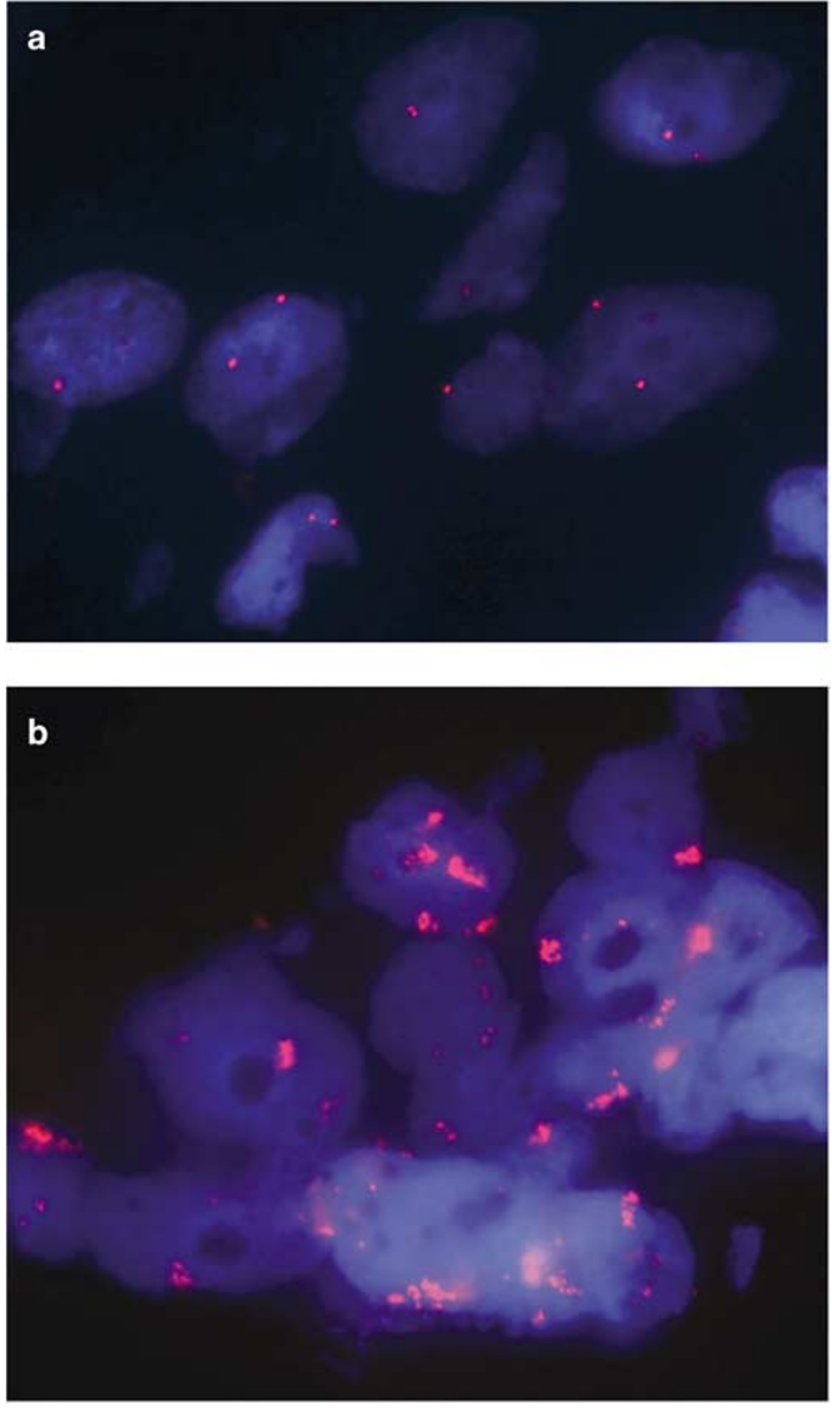

Figure 2 Fluorescence images showing several tumor cells with 1-2 egfr gene copies each (a), and a tumor cell population with strong egfr amplification (b).

\section{Materials and methods}

\section{Samples}

A total of 222 cases of invasive female breast carcinomas were retrieved from the files of the Institute of Pathology, University of Muenster. Material underwent fixation in $4 \%$ buffered formaldehyde and was embedded in paraffin according to standard protocols. Tumor samples were graded according to established recommendations. ${ }^{16}$ A total of 64 low-grade carcinomas, 120 intermediate and 29 high-grade breast carcinomas were included.

\section{Tissue Microarray Construction}

Using the tissue microarray technique, ${ }^{17,18}$ an array consisting of 444 cores with a diameter of $0.6 \mathrm{~mm}$. 
each and a distance of $0.2 \mathrm{~mm}$ was composed. For location of representative tumor areas, hematoxylinand eosin-stained sections were prepared from each original tumor block. Two cores per specimen were punched out using a TMA instrument (Beecher Instruments, Silver Spring, MD, USA).

\section{DNA Extraction}

Two representative needle core biopsies from each tumor sample of on average $0.3 \mathrm{~cm}$ length were punched out, deparaffinized with xylene and ethyl alcohol and lysed with proteinase K (DAKO). DNA extraction was then performed on a Tecan Genesis Workstation RSP 150 instrument (Tecan Germany, Crailsheim) using a magnetic bead separation technique (AGOWA mag Maxi DNA Isolation Kit; AGOWA GmbH, Germany). The procedure was performed according to the manufacturer's instructions.

\section{Quantitative Real-time PCR ( $5^{\prime}$ nuclease assay)}

For detection of amplifications containing the first CA repeat in the first intron of the egfr gene, a quantitative realtime PCR was performed targetting the repeat, and two known single-copy genes, ${ }^{19}$ superoxide dismutase (SOD) and hemoglobin beta (HBB) genes, as reference (Figure 3).

Specific primers for sequences flanking the first CA repeat in the first intron of the egfr gene were designed (CAIfor: $5^{\prime}$-tgaagaatttgagccaaccaaa- $3^{\prime}$ and CAIrev: $5^{\prime}$-cacttgaaccagggacagca- $3^{\prime}$ ) using Primer Express software (Applera). They were chosen since previous studies demonstrated that this primer combination defines amplifications of the whole gene, amplifications restricted to the CA-SSR I repeat and mutations involving this polymorphic sequence. Also a universal, VIC labeled probe consisting of 15 CA repeats (minor groove binder probe: nine repeats) was constructed. The primers were checked by BLAST search (Internet address: http://www.ncbi.nlm.nih.gov/Sitemap/ index.html\#BLAST) and represented specific sequences for egfr. Primers and probes were also designed for the single-copy genes SOD2 (chromosome 6q25, GenBank accession no.

65965, forward primer: 5'-GGAGAAGCTGAC GGCTGC-3', reverse primer: 5'-CCTTATTGAAACC AAGCCAACC-3', VIC-labeled probe: $5^{\prime}$-CAACCTG AGCCTTGGACACCAACAGA-3 ${ }^{\prime}$ ) and HBB (chromosome 11p, GenBank accession No. V00499, forward primer: 5'-GTGAAGGCTCATGGCAAGAAAG-3' , reverse primer: 5'-CAGCTCACTCAGTGTGGCAAAG3', VIC-labeled probe: ATGGCCTGGCTCACCTGGA CAACC). The amplicon length was minimized (68-97 bp) for all three of the genes, to allow for the most efficient PCR amplification. PCR analysis was performed using TaqMan Universal Mix (Applera) and detection was performed on an ABI Prism 7900HT Sequence Detection System (Applera). Cycling conditions were as follows:

Denaturation: $95^{\circ} \mathrm{C}, 15 \mathrm{~s}$, annealing and extension $60^{\circ} \mathrm{C}, 1 \mathrm{~min}$, using 40 cycles. All PCR reactions were performed in triplicate and in at least two independent reactions. Serial dilutions of DNA were used to ensure accuracy of gene dosage quantification. The copy number of the egfr gene was measured in the breast cancer-derived cell line MDA-MB-468 in comparison to normal leukocytes. MDA-MB-468 DNA reportedly displays a 30-50-fold amplification
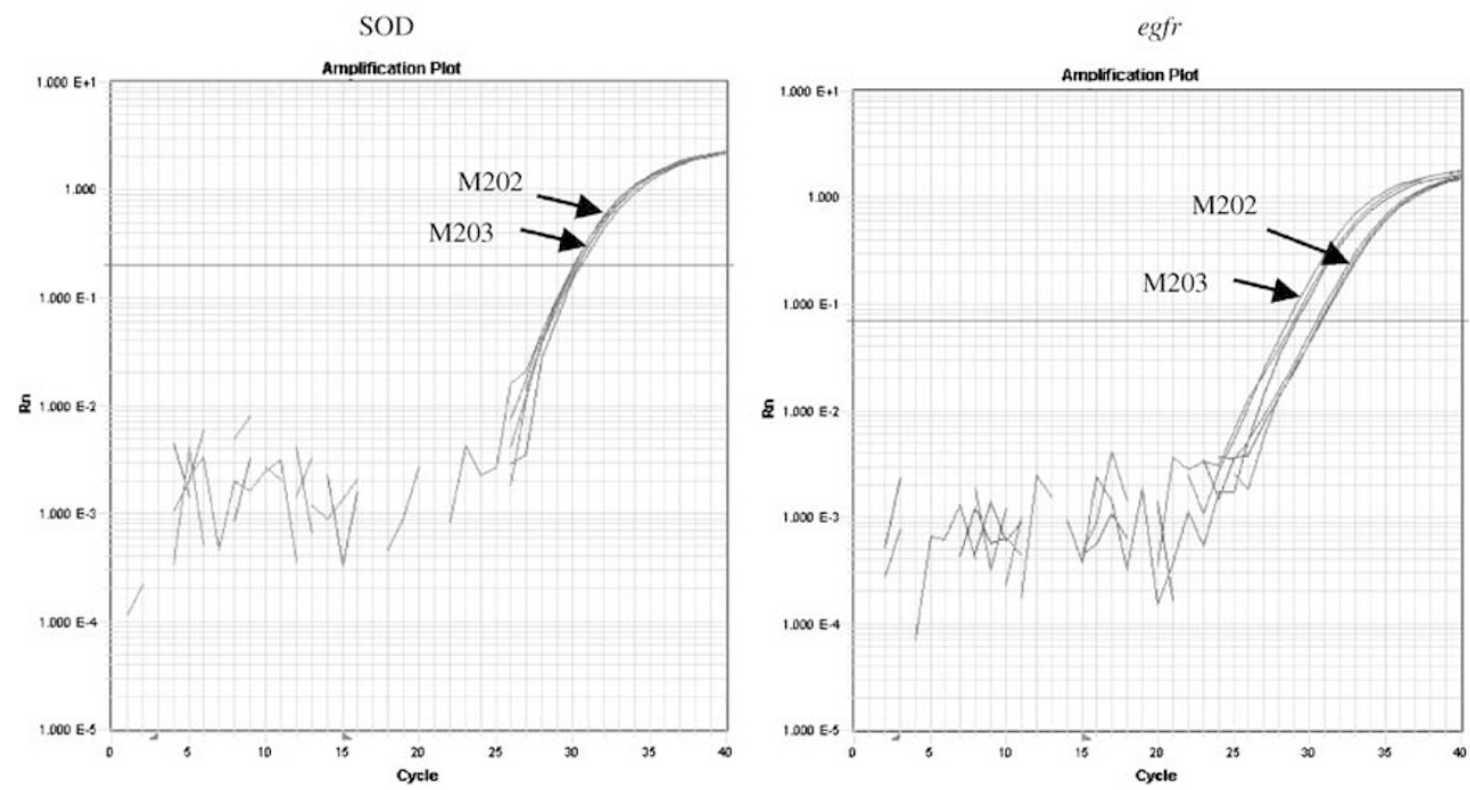

Figure 3 Diagram of gene dosage PCR showing elevated egfr amplicon concentration of a sample with $4 \times$ egfr amplification (M203) compared to a sample without amplification (M202). The concentration of the reference gene amplicon (SOD) is equal in both samples. 
of the egfr gene ${ }^{20}$ and was used as a positive control. DNA concentrations were normalized to both SOD2 and $H B B$.

\section{Immunohistochemistry}

After deparaffination and rehydration, endogenous peroxidase activity was blocked for $30 \mathrm{~min}$ in a methanol solution containing $0.3 \%$ hydrogen peroxide. After antigen retrieval in citrate buffer in an autoclave, a cooling off period of $30 \mathrm{~min}$ preceded the incubation (overnight at $4^{\circ} \mathrm{C}$ ) with a primary EGFR antibody (Novocastra) diluted 1:10. The primary antibodies were detected using a biotinylated rabbit anti-mouse antibody (DAKO). The signal was amplified by avidin-biotin complex formation and developed with diaminobenzidine followed by hematoxylin counter staining. Before the slides were mounted all sections were dehydrated in alcohol and xylene.

Slides with exchange of the specific antibody with PBS buffer and slides with a non-EGFR expressing cell line (SKBR-3) served as negative controls. Furthermore, a slide with an EGFR overexpressing human breast cancer cell line (MDA-MB486) was used as positive control. Membrane expression was graded from 0 to 3 (in the style of DakoScore for HER-2/neu). For further analysis, cases with a score $>1$ were regarded as showing overexpression.

\section{Fluorescence In Situ Hybridization}

The probe for egfr detection was derived from Homo sapiens PAC clone containing the whole egfr gene (GenBank accession no. AC006977). DNA was labeled with digoxigenin-11-dUTP by nick translation following standard protocols. The probe was denatured for $5 \mathrm{~min}$ at $70^{\circ} \mathrm{C}$ in $70 \%$ formamid$0.6 \times$ SSC. Hybridization to TMA sections of $2 \mu \mathrm{m}$ thickness was carried out overnight at $37^{\circ} \mathrm{C}$ in a $50 \%$ formamid-1 $\times$ SSC-10\% dextran sulfate solution in the presence of Cot-1-DNA (Life Technologies, Inc., Carlsbad, USA) and HPL-DNA (Sigma, St Louis, USA). Posthybridization washes were performed at $45^{\circ} \mathrm{C}$ in $50 \%$ formamide- $2 \times$ SSC and $0.1 \times$ SSC at $60^{\circ}$ followed by blocking with $3 \%$ BSA in $4 \times$ SSC at $37^{\circ} \mathrm{C}$. Probe detection was performed using mouse-anti-digoxigenin (Sigma, St Louis, USA) and Cy3-labeled goat-antimouse antibodies (Dianova $\mathrm{GmbH}$, Hamburg, Germany) for $45 \mathrm{~min}$ each at $37^{\circ} \mathrm{C}$

For each core, 20 nuclei were selected for scoring according to morphological criteria using DAPI counterstaining. Only nonoverlapping, intact nuclei were scored. Clearly distinguishable nontumor cells were disregarded. Thresholds for DNA copy number were defined by scoring of 200 nuclei in normal mammary tissue sections. Scoring was performed as previously published. ${ }^{21}$

\section{Statistical Analysis}

Statistical analysis and tests were performed with SPSS Version 11.5. 1. Crosstables were made and Pearson's $\chi^{2}$ - test or Fisher's exact test, when appropriate, were calculated.

\section{Results}

Distribution of TNM stage in patients with complete TNM assessment was as follows: T1 $36.8 \%$; T2 $39.6 \%$; T3 $7.6 \%$; T4 16\%; $N>050.4 \% ; M=110.6 \%$. With FISH, $76.6 \%$ of cases could be analyzed $(n=170)$, of which $8(4.7 \%)$ showed amplification. The other $24.4 \%$ of specimens could not be evaluated due to loss of cores on the slide used for FISH-analysis or because of uninterpretable results of the hybridization itself.

An amplification of the first CA repeat in the first intron of the egfr gene was detected in eight cases $(6.3 \%)$. Amplification dosage varied between twoand four-fold. By immunohistochemistry, 179 specimens $(80.6 \%)$ could be analyzed of which 31 $(17.3 \%)$ showed overexpression of EGFR.

Tables 1-4 show the comparisons between FISH, immunohistochemistry and gene dosage PCR. FISH was correlated with gene dosage PCR (Table 1, $P=0.004)$. In all, $2.9 \%$ of cases showed both whole gene amplification and intron CA repeat amplification, and $90.3 \%$ of cases were negative for both. As shown in Table 2, also immunohistochemistry and intron CA repeat amplification were correlated $(P=0.01)$. In all, $20 \%$ of cases with immunohisto-

Table 1 Comparison between gene dosage PCR to assess egfr intron 1 CA repeat amplification and FISH to assess whole gene amplification in invasive breast cancer

\begin{tabular}{llrc}
\hline & & \multicolumn{2}{c}{ FISH } \\
\cline { 3 - 4 } & & Negative & Positive \\
\hline Intron 1 CA repeat amplification & Negative & 93 & 4 \\
& Positive & 3 & 3 \\
\hline
\end{tabular}

$P=0.004$

Table 2 Comparison between gene dosage PCR to assess egfr intron 1 CA repeat amplification and EGFR overexpression by immunohistochemistry in invasive breast cancer

\begin{tabular}{llcc}
\hline & & \multicolumn{2}{c}{$\begin{array}{c}\text { Intron 1 CA repeat } \\
\text { amplification }\end{array}$} \\
\cline { 3 - 4 } & & Negative & Positive \\
\hline Immunohistochemistry & Negative & 86 & 2 \\
& Overexpression & 16 & 4 \\
\hline
\end{tabular}

$P=0.01$ 
Table 3 Comparison between FISH to assess egfr whole gene amplification and EGFR overexpression by immunohistochemistry in invasive breast cancer

\begin{tabular}{llrc}
\hline & & \multicolumn{2}{c}{ FISH } \\
\cline { 3 - 4 } & & Negative & Positive \\
\hline Immunohistochemistry & Negative & 122 & 2 \\
& Overexpression & 20 & 3 \\
\hline
\end{tabular}

$P=0.027$.

Table 4 Comparison of egfr amplification of the whole gene by FISH or the intron 1 CA repeat by gene dosage PCR and EGFR overexpression by immunohistochemistry in invasive breast cancer

\begin{tabular}{llcc}
\hline & \multicolumn{2}{c}{$\begin{array}{c}\text { Amplification for } \\
\text { either the whole gene } \\
\text { or the first intron } \\
\text { CA repeat }\end{array}$} \\
\cline { 2 - 3 } & \multicolumn{2}{c}{$\begin{array}{c}\text { Both } \\
\text { negative } \\
(\%)\end{array}$} & $\begin{array}{c}\text { Either } \\
\text { positive } \\
(\%)\end{array}$ \\
\hline Immunohistochemistry & $\begin{array}{c}\text { Negative } \\
\text { Overexpression }\end{array}$ & $\begin{array}{c}94.8 \\
75\end{array}$ & $\begin{array}{c}5.2 \\
25\end{array}$ \\
\hline
\end{tabular}

$P=0.022$.

chemical protein overexpression showed intron CA repeat amplification, and only $2.2 \%$ of cases that were negative on immunohistochemistry showed such amplification. As shown in Table 3, immunohistochemistry and FISH were correlated $(P=0.027)$. In all, $13 \%$ of cases with immunohistochemical protein overexpression showed amplification by FISH, and only $1.6 \%$ of cases that were negative on immunohistochemistry showed such amplification. Of the cases with overexpression of EGFR, four (25\%) showed either whole gene or intron CA repeat amplification $(P=0.022$, Table 4$)$.

No relationship between TNM stage and EGFR status could be confirmed with either modality in the present study.

\section{Discussion}

The aim of this study was to assess the frequency of egfr whole gene and CA intron repeat amplification in invasive breast cancer as a mechanism for EGFR protein overexpression.

Many years ago, egfr gene amplification was proposed as a possible cause for EGFR overexpression in breast cancer, ${ }^{22}$ but recent publications indicate that the strict gene-dosage interaction as for c-erbB2 regulation does not hold for EGFR. ${ }^{15,23}$ This assumption is confirmed by our present data. A striking discrepancy between EGFR expression $17.3 \%(17.3 \%)$ and egfr whole gene amplification
$(4.7 \%)$ could be observed. Although indeed most cases with EGFR whole gene amplification showed overexpression, $86.9 \%$ of cases with protein overexpression showed no gene amplification. Several explanations might account for this finding. Lately, modulation of transcription by secondary structures and polymorphic short sequence repeats residing within the egfr gene ${ }^{13}$ have been described. These kind of changes are not revealed by FISH. A recent study on microsatellite alterations in regulating sequences of $e g f r^{15,23}$ indicated that amplifications including intron 1 sequences of egfr seem to be involved in EGFR overexpression in breast carcinoma. To increase detection sensitivity, we have therefore chosen a PCR assay targeting this region, assuming that with this approach, most of the lowscale genetic alterations in egfr can be detected. As expected, ${ }^{24}$ the detection rate for egfr intron CA repeat amplifications is slightly higher, namely $6.3 \%$, pointing to the fact that the PCR approach might be the more sensitive method. Unfortunately, the sensitivity of this technique is not optimal yet. A noticeably lower number of amplifications and also lower amplification levels in paraffinembedded material as in fresh tumor samples were observed. $^{2,15}$ As a consequence, either further optimization has to be done, or investigation with the PCR technique should focus on fresh frozen tumor samples rather than paraffin-embedded material. With this technique, intron CA repeat amplifications were detected in $6.3 \%$ of cases. A total of $50 \%$ of these had protein overexpression, further underlining the importance of this amplification in regulation of EGFR protein expression. In all, $55.5 \%$ of cases with either whole gene or intron CA repeat amplification had EGFR protein overexpression and only $25 \%$ of cases with EGFR protein overexpression showed either whole gene or intron CA repeat amplification. This indicates that still other mechanisms, such as post-translational changes or length polymorphisms in intron 1 of egfr, ${ }^{23,25}$ may regulate EGFR protein expression. These issues require further investigation. Also the predictive value of the amplification detection techniques with regard to response to EGFR targeting therapies deserves to be further studied. Another issue to be discussed is the usage of tissue microarrays. The samples may not always be representative for the whole tumor. Therefore, two cores were punched out of each tumor. In addition, cores used for immunohistochemistry, FISH and PCR were taken in close vicinity. With this approach, the tumor samples retained the highest possible comparability. Using TMAs, the detection rate of EGFR overexpression might be lower than with the use of whole tissue sections. It should therefore be kept in mind that the level of correlation with FISH and PCR might even be exaggerated.

In conclusion, whole gene amplifications of egfr are rare in invasive breast cancer and explain protein overexpression in only about $12.5 \%$ of 
invasive breast cancer cases. First intron first CA repeat amplification is another important mechanism for EGFR protein overexpression, explaining protein overexpression in about $18.7 \%$ of cases. However, since about $75 \%$ of cases with EGFR protein overexpression lack either of these amplifications, other expression regulating mechanisms must be considered.

\section{Acknowledgement}

We thank Mrs Katrin Blaschei, Mrs Petra Meier, Mrs Gabriele Klapdor and Mrs Petra van der Groep for excellent technical assistance. Supported in part by the unrestricted First International Scholarship in Oncology from Aegon Inc.

\section{References}

1 Di Fiore PP, Pierce JH, Fleming TP, et al. Overexpression of the human EGF receptor confers an EGFdependent transformed phenotype to NIH 3T3 cells. Cell 1987;6:1063-1070.

2 Ro J, North SM, Gallick GE, et al. Amplified and overexpressed epidermal growth factor receptor gene in uncultured primary human breast carcinoma. Cancer Res 1988;48:161-164.

3 Guerin M, Gabillot M, Mathieu MC, et al. Structure and expression of c-erbB-2 and EGF receptor genes in inflammatory and non-inflammatory breast cancer: prognostic significance. Int J Cancer 1998;43:201-208.

4 Witton CJ, Reeves JR, Going JJ, et al. Expression of the HER1-4 family of receptor tyrosine kinases in breast cancer. J Pathol 2003;3:290-297.

5 Sainsbury JR, Farndon JR, Needham GK, et al. Epidermal-growth-factor receptor status as predictor of early recurrence of and death from breast cancer. Lancet 1987;20:1398-1402.

6 Costa S, Stamm H, Almendral A, et al. Predictive value of EGF receptor in breast cancer. Lancet 1988; 8622:1258.

7 Pawlowski V, Révillion F, Hebbar M, et al. Prognostic value of the type I growth factor receptors in a large series of human primary breast cancers quantified with a real-time reverse transcription-polymerase chain reaction assay. Clini Cancer Res 2000;6:4217-4225.

8 Fitzgibbons PL, Page DL, Weaver D, et al. Prognostic factors in breast cancer. College of American Pathologists Consensus Statement 1999. Arch Pathol Lab Med 2000;7:966-978.

9 Atalay G, Cardoso F, Awada A, et al. Novel therapeutic strategies targeting the epidermal growth factor receptor (EGFR) family and its downstream effectors in breast cancer. Ann Oncol 2003;14:1346-1363.
10 Harris AL. What is the biological, prognostic, and therapeutic role of the EGF receptor in human breast cancer? Breast Cancer Res Treat 1994;29:1-2.

11 Dancey JE, Freidlin B. Targeting epidermal growth factor receptor-are we missing the mark? Lancet 2003;362:62-64.

12 Ciardiello F, Tortora G. Anti-epidermal growth factor receptor drugs in cancer therapy. Exp Opin Invest Drugs 2000;11:755-768.

13 Gebhardt F, Bürger H, Brandt B. Modulation of EGFR gene transcription by secondary structures, a polymorphic repetitive sequence and mutations-a link between genetics and epigenetics. Histol Histopathol 2000;15:929-936.

14 McInerney JM, Wilson MA, Strand KJ, et al. A strong intronic enhancer element of the EGFR gene is preferentially active in high EGFR expressing breast cancer cells. J Cell Biochem 2001;4:538-549.

15 Tidow N, Boecker A, Schmidt H, et al. Distinct amplification of an untranslated regulatory sequence in the egfr gene contributes to early steps in breast cancer development. Cancer Res 2003;6:1172-1178.

16 Ellis IO, Elston CW. Tumors of the breast. In: Fletcher CDM (ed). Diagnostic Histopathology of Tumors. Churchill Livingstone: New York, 1998, pp 635-689.

17 Kononen J, Bubendorf L, Kallioniemi A, et al. Tissue microarrays for high-throughput molecular profiling of tumor specimens. Nat Med 1998;4:844-847.

18 Packeisen J, Korsching E, Herbst H, et al. Demystified...tissue microarray technology. Mol Pathol 2003;56:198-204.

19 Brandt B, Vogt U, Harms F, et al. Double-differential PCR for gene dosage estimation of erbB oncogenes in benign and cancer tissues and comparison to cellular DNA content. Gene 1995;159:29-34.

20 Rötger A, Brandt B, Barnekow AA. Competitive differential PCR method for gene dosage estimation of erbB-1 (egfr), erbB-2, and erbB-3 oncogenes. DNA Cell Biol 1997;16:443-448.

21 Steidl C, Simon R, Burger H, et al. Patterns of chromosomal aberrations in urinary bladder tumours and adjacent urothelium. J Pathol 2002;198:115-120.

22 Lebeau J, Goubin G. Amplification of the epidermal growth factor receptor gene in the BT20 breast carcinoma cell line. Int J Cancer 1987;40:189-191.

23 Buerger H, Gebhardt F, Schmidt H, et al. Length and loss of heterozygosity of an intron 1 polymorphic sequence of egfr is related to cytogenetic alterations and epithelial growth factor receptor expression. Cancer Res 2000;60:854-857.

24 Hunter SB, Abbott K, Varma VA, et al. Reliability of differential PCR for the detection of EGFR and MDM2 gene amplification in DNA extracted from FFPE glioma tissue. J Neuropathol Exp Neurol 1995;54: 57-64.

25 Gebhardt F, Zanker KS, Brandt B. Modulation of epidermal growth factor receptor gene transcription by a polymorphic dinucleotide repeat in intron 1 . J Biol Chem 1999;274:13176-13180. 